\title{
A FACE OCULTA NA PREVENÇÃO DA AIDS
}

[The hidden face on the AIDS prevention]

\author{
Valéria Silvana Faganello Madureira* \\ Mercedes Trentini**
}

RESUMO: Trata-se de uma reflexão sobre o crescimento da epidemia de HIV/aids entre pessoas de orientação heterossexual, especialmente aquelas que mantêm um relacionamento afetivosexual estável, e sobre as interações poder-gênero envolvidas neste crescimento. A partir disto, pensase a educação em saúde para prevenção das DST/ AIDS na prática cotidiana da enfermagem, apontando a necessidade de adoção de uma postura menos prescritiva e mais compreensiva que possibilite o diálogo com homens e mulheres sobre uma série de questões de seu viver íntimo também envolvidas na determinação da vulnerabilidade de ambos às DST/AIDS.

PALAVRAS-CHAVE: gênero; poder; relações de casal; prevenção de AIDS.

\section{INTRODUÇÃO}

Este artigo propõe-se fazer uma reflexão sobre o crescimento da epidemia de HIVIAIDS entre pessoas de orientação heterossexual, especialmente dentre aqueles que mantêm um relacionamento afetivo-sexual estável, e sobre as interações poder-gênero envolvidas neste crescimento. Para tanto, é importante relembrar um pouco da história.

No início dos anos 80, a AIDS surgiu no cenário internacional com tal força que logo assumiu o caráter de pandemia e, desde então, tem sido

\footnotetext{
*Enfermeira, aluna do curso de doutorado em Enfermagem da Universidade Federal de Santa Catarina - UFSC; professora da Universidade do Contestado - UnC Concórdia SC; bolsista CNPq. **Doutora em Enfermagem; professora aposentada da UFSC; professora visitante da PUC Paraná.
}

relacionada a pessoas cujo comportamento sexual foge do tradicionalmente esperado para homens e mulheres na sociedade. Desta forma, foi rotulada como câncer gay em função dos primeiros casos terem sido diagnosticados em grupos de homossexuais masculinos, postura respaldada e reforçada cientificamente posto que, à época, a ciência pouco conhecia sobre o vírus, sua ação no organismo, suas formas de transmissão e não antecipava as dimensões sociais que tomaria. Esta vinculação a grupos de risco fomentou a discriminação e a percepção da aids como doença dos outros (CAMPOS, 1998).

Aos poucos esta visão foi modificando e passou a incluir bissexuais masculinos e homens usuários de drogas. Entretanto, esta postura inicial teve efeitos ainda hoje sentidos, pois levou as pessoas em geral a acreditar que se encontravam fora de risco. De acordo com Parker e Galvão (1996), no imaginário social, a AIDS tem sido vista como um fenômeno masculino desde o início dos anos 80. Além disso, no início da epidemia as iniciativas de prevenção faziam duas recomendações: reduzir o número de parceiros sexuais e conhecer o parceiro, o que cultivou a idéia de que agindo assim as pessoas em geral não estariam expostas a riscos. Entretanto, com o passar do tempo o número de casos aumentou disseminando-se pelo tecido social e promovendo a visualização da AIDS como doença de todos (CAMPOS, 1998).

O rápido crescimento daAIDS entre mulheres foi um indicador da mudança no perfil epidemiológico da epidemia e chamou a atenção para as relações heterossexuais. Isto ficou particularmente visível na década de $90 \mathrm{com}$ o aumento no número de mulheres infectadas em relação sexual com parceiros contaminados pelo 
HIV. Isso evidenciou o crescimento da epidemia no âmbito do lar, muito além das fronteiras dos comportamentos sexuais considerados de risco como prostituição, homossexualidade e uso de drogas injetáveis. Mas apesar da heterossexualidade representar o 'normal' sócioculturalmente instituído no campo das relações afetivo-sexuais, o que se passa na intimidade do casal é ainda um enigma, cuja compreensão deficiente evidencia-se no crescimento da AIDS por contaminação heterossexual, e nas diferenças entre o que as iniciativas de prevenção no país propõem e o que de fato acontece no viver concreto de homens e mulheres. Tudo o que consideramos como risco para aids se passa no contexto da interação entre pessoas, em espaço privado, não podendo ser controlado, punido ou vigiado publicamente a não ser por seus efeitos (PAIVA, 2000).

Desta forma, as características atuais da epidemia que revelam a presença da AIDS nas relações heterossexuais consideradas estáveis, apresentam um bom argumento para a compreensão destas relações intensamente marcadas por relações de gênero e poder.

\section{PODER E GÊNERO}

O poder não tem localização definida, é disseminado pelo corpo social, envolve a todos e atua na produção de cada indivíduo (FOUCAULT, 1995; 2001). Desta forma, o poder não é algo que alguém possua e outros não, pois embora uma relação de poder sempre pressuponha assimetria de posições, o outro sempre tem possibilidade de resistência, a qual se localiza internamente à própria trama das relações de poder e que se configura em contra-poder.

O poder é assim visto de forma positiva, com ênfase em sua força produtiva que tem a produção do sujeito como um de seus principais resultados. Sob esta perspectiva, o poder tem um caráter relacional fundamental, isto é, ele só se exerce em relação. É possível também pensar nas relações de poder como um jogo no qual ele oscila, variando de intensidade entre os que dele participam. Não há nada fixo, mas mobilidade, transitoriedade e a possibilidade sempre presente de inversão de posições. Nesta forma de pensar as relações de poder, as polaridades da relação dominador- dominado tão freqüentemente relacionadas a ela são incompatíveis, justamente por remeterem a posições fixas, a uma unidirecionalidade de forças e à face negativa, repressiva do poder.

Foucault situa o poder na vida cotidiana de cada um, considerando-o imanente a todas as relações. Isso confere outras nuanças às relações, inclusive àquelas sempre pensadas em termos de dominação nas quais um dos sujeitos é colocado na posição de vítima, de submissão. Um exemplo disso pode ser percebido na forma como as relações entre homem e mulher são representadas, com a mulher na maioria das vezes considerada como pólo sobre o qual incide o poder do homem.

Entretanto, se olharmos para estas relações considerando o poder como um "feixe de relações mais ou menos organizado, mais ou menos piramidalizado, mais ou menos coordenado" (FOUCAULT, 1995, p.48), será possível intuir o movimento a elas inerentes, embora não possamos negar a existência de relações de dominação. Este é o espaço das relações heterossexuais, construído no encontro de homens e mulheres, de feminilidades e masculinidades, produzidas nas relações sociais segundo as normas que as caracterizam em cada sociedade. No contexto das relações de casal, a conjugalidade heterossexual é estabelecida como normal e é a partir dela que as outras formas de relacionamento se constituem como diferentes. Essa conjugalidade normalizada pressupõe um ideal de homem, um ideal de mulher, um ideal de relação, com papéis e lugares femininno e masculino já delimitados, de acordo com o que é sócio-culturalmente construído e aceito como normal. Isso nos remete a outro aspecto das relações de poder e, de resto, de todas as relações sociais: a sua generificação. Gênero, relações de poder e relações sociais imbricam-se, retroalimentam-se e constroem-se mutuamente. Não é possível imaginá-las como três vertentes separadas que circulam paralelamente pelo corpo social, mas, ao contrário, como um emaranhado que se envolve no corpo social.

Gênero faz referência ao processo social, histórico e cultural de construção do ser homem e do ser mulher, de masculinidade e de feminilidade. O biológico também faz parte deste processo, pois é no corpo que as marcas sócio-culturais se inscrevem; é em função do corpo e do sexo 
biológico que somos significados como homens e mulheres.

Negados os essencialismos e os determinismos, é possível dizer que em diferentes sociedades, em diferentes contextos culturais a compreensão de masculino e feminino difere, bem como o caráter das relações de poder que entre eles circulam. Desta forma, MULHER e HOMEM não existem como duas grandes categorias neutras e universais, mas como sujeitos diversos constituídos nas/pelas relações sociais.

A essencialização das diferenças pautada na biologia fixa tanto homem como mulher em posições polares, contrapostas e irredutíveis, compondo uma lógica binária que condiciona nossa maneira de perceber o mundo, tornando difícil concebê-lo de outra forma (LOURO, 1998). Essa lógica dicotômica revela-se em uma série de oposições comumente usadas em referência ao masculino e ao feminino, nos quais o primeiro termo designa o masculino e o segundo, o feminino, numa indicação de que os lugares do feminino são constituídos a partir dos lugares do masculino. Exemplos clássicos destas oposições são as relações binárias público/privado, razão/emoção, ativo/passivo, forte/fraco, dominador/dominado, tão presente no cotidiano a ponto de serem interpretadas e aceitas como naturais, sem que nos apercebamos que elas oferecem parâmetros para circunscrever os espaços masculinos e femininos, instituindo normas para o ser homem e o ser mulher. É preciso desconstruir essa lógica para que seja possível reconhecer a interdependência dos pólos bem como as diferenças existentes em cada um deles. Isso nos remete à consideração de que gênero não é um conceito a ser utilizado para substituir a palavra 'sexo'e que não se restringe às relações entre homens e mulheres. Gênero inclui relações entre homens e entre mulheres, evidenciando o reconhecimento das diferenças intragênero. Mas é principalmente dentro desta lógica que homens e mulheres, masculino e feminino se constituem, bem como os seus lugares na sociedade. Neste processo, as diferenças biológicas têm servido como fundamento natural que justifica desigualdades em todos os setores do viver, seja no plano mais íntimo e familiar, seja no espaço de leis e políticas públicas. Desta forma, estão dadas as assimetrias entre homens e mulheres, perceptíveis no cotidiano se nos detemos a observá-las, mas também tão naturalmente vividas pela maioria das pessoas que as vêem como fato e, na maioria das vezes, irremediável. As assimetrias abrem o espaço ideal para o exercício do poder que circula entre sujeitos que ocupam posições diferentes, assimétricas, mesmo que a assimetria seja de caráter provisório. Por vezes, essas assimetrias são marcadas por relações tão fixas que se caracterizam como repressão ou dominação. Mesmo nestas relações há possibilidade de resistência, manifestada mesmo que seja em pequenas astúcias cotidianas que não possibilitam a inversão de posições (FOUCAULT, 1995).

Essa compreensão nos provoca a considerar o jogo de poder na conjugalidade heterossexual, a qual no mais das vezes se constitui sobre o pano de fundo das polaridades de gênero, em que os papéis sexuais são bem definidos. De acordo com esses papéis, cabe à mulher o segundo pólo nas dicotomias anteriormente apontadas, ao qual se reserva o mundo do lar, circunscrito no âmbito do privado de acordo com as normas de uma sociedade de herança patriarcal. Já aos homens está reservado o espaço da rua, o mundo público.

Esta fórmula tradicional de conjugalidade se mantém e delimita o espaço socialmente demarcado para o relacionamento sexual, regulado por uma série de leis e normas sociais, culturais e religiosas. É importante que se faça uma referência à dupla moral sexual que vigora para 0 comportamento sexual de homens e mulheres, de acordo com a qual espera-se das mulheres um comportamento mais contido, reservado, com um único parceiro com o qual ela mantenha um relacionamento estável e, de preferência, formalizado pelo casamento. Para os homens, as expectativas são outras, menos restritivas, com um comportamento sexual mais ativo, mais agressivo, o que também normatiza o ser homem definindo uma masculinidade normal (PARKER, 1991). Desta forma, os homens são estimulados e incentivados à multiparceria sexual e as mulheres, ao relacionamento com um único parceiro. Isto estabelece um aspecto da masculinidade e da feminilidade ideais que, quando transgredido, expõe o transgressor à recriminação e revela uma 
verdade íntima sobre ele, classificando-o na categoria 'outros'. Neste espaço inscreve-se também a sexualidade, dispositivo de constituição do sujeito (FOUCAULT, 1995), no âmbito da qual encontramos as Doenças Sexualmente Transmissíveis (DST), relacionadas a práticas e comportamentos que, de certa forma, revelam a identidade de quem as tem, revelam o que o sujeito É.

Relacionadas com práticas e comportamentos sexuais, as DSTs vêm carregadas por um forte preconceito e não parecem estar de acordo com os perfis ideais de mulher e homem socialmente construídos. Não são doenças de mães e esposas, segundo a representação que delas se tem na sociedade, e, embora sejam geralmente consideradas como parte do universo masculino em que a 'prontidão para o sexo' é tida como normal, não o são no universo do esposo e pai de família. Entretanto, na vida cotidiana os universos masculino e feminino, público e privado não são assim tão separados e as DST sempre transitaram entre eles, embora cercadas por silêncio, mistério, segredo e vergonha. A emergência da AIDS pôs a público o que sempre fora considerado questão íntima, dando mais relevo às discussões sobre sexo e sexualidade, comportamentos e práticas sexuais, orientações sexuais, todos diretamente envolvidos na transmissão da doença.

\section{RELACIONAMENTO HETEROSSEXUAL E PREVENÇÃO DE AIDS}

As relações heterossexuais, consideradas como socialmente 'normais', são reguladas por uma série de princípios. Muitos destes princípios são pressupostos e acredita-se que não precisem ser explicitados posto que 'temperam'o viver em casal. Aqui poderíamos incluir a pressuposição da existência de amor e da necessidade de confiança, fidelidade e exclusividade. Além destes, é amplamente reconhecido como o 'espaço ideal' para o relacionamento sexual entre homens e mulheres e para ter filhos.

O simples reconhecimento destes princípios cria outras suposições como, por exemplo, a de que certos assuntos não precisam ser falados, pois colocariam em dúvida a existência dos mesmos e o respeito a eles. Criam-se, assim, grandes zonas de silêncio que impedem ou dificultam o diálogo em torno de questões íntimas como a sexualidade do casal. Afinal, por que falar da qualidade do relacionamento sexual se um ama o outro? Ou então, por que discutir sobre contracepção, se são as mulheres que ficam grávidas e dispõem de anticoncepcionais seguros para evitar uma gravidez? Ou ainda, por que discutir o uso do preservativo masculino e incluir no relacionamento de casal uma 'sombra'que põe em dúvida a confiança mútua, a fidelidade e a exclusividade afetivo-sexual? Ou também, por que discutir o uso do preservativo se a mulher fez laqueadura e não engravidará mais?

Aqui ficam evidentes as características de gênero que normatizam diferenças entre homens e mulheres no campo da sexualidade. Segundo essas características, uma mulher com um parceiro estável não deverá ter outros parceiros; ao mesmo tempo, para adequar-se a um perfil de masculinidade dominante, o homem pode ter várias parceiras e não deixar passar nenhuma oportunidade de manter uma relação sexual, isto é, torna-se difícil para ele dizer 'não'sob pena de ser considerado menos homem.

É possível, então, crer que a sexualidade feminina se situe no mundo dos afetos, estando o seu exercício condicionado à existência de uma relação, enquanto que a sexualidade masculina é tida como necessidade biológica, o que permite a busca incondicional de satisfação (VILLELA, 1996).

Neste contexto, a simples abordagem do tema sexo seguro fica difícil, pois subentende-se que o sexo no casal seja seguro pela própria natureza da relação. Neste contexto, a discussão sobre o uso do preservativo masculino, com maior disponibilidade no mercado, de preço mais acessível e distribuído pelo Ministério da Saúde parece incompatível. Talvez pudéssemos dizer que as características de gênero enfraquecem tanto homens como mulheres nos seus relacionamentos de casal, impedindo-os de manter diálogo franco sobre diversos temas cotidianos, dentre os quais a sexualidade. Como pode uma mulher falar sobre o uso da camisinha com seu parceiro sem acreditar que ele duvidará da fidelidade dela ou que ele pensará que ela desconfia dele? Como pode um homem passar a usar preservativo no seu relacionamento de casal sem assumir que tem 
alguma coisa 'fora'de casa? Nestes casos, além da confiança mútua, a própria certeza do amor de um pelo outro pode ser colocada em dúvida, ameaçando a sobrevivência da relação. Então, estando as relações heterossexuais marcadas pelo gênero e pelo poder que circula entre mulher e homem, o que é comumente reforçado por fortes assimetrias de gênero, torna-se difícil para o casal negociar os termos de um encontro sexual, especialmente se o contexto deste encontro for um relacionamento estável. Isto pode ser particularmente verdadeiro para as mulheres, as quais têm tido sua sexualidade vinculada à reprodução e podem ter uma percepção reprodutora de si mesmas (GUIMARÃES, 2001), o que dificulta a auto-proteção e ao mesmo tempo torna difícil a negociação das trocas que se estabelecem entre o casal (BARBOSA, 2000).

$O$ reconhecimento do relacionamento heterossexual estável como o espaço ideal para ter filhos, faz com que homens e mulheres envolvidos neste tipo de relação tenham a gravidez como preocupação principal e a contracepção como necessidade central. Aliando-se essa compreensão aos princípios acima abordados, pode parecer que o uso do preservativo seja incompatível com estas relações, pois sugere desconfiança e questiona a fidelidade, o amor ao outro e a exclusividade afetivosexual. Isso coloca a contracepção no âmbito da vulnerabilidade e a noção de dupla proteção como necessária ao trabalho preventivo, pois atribui igual valor à prevenção de gravidez e de DSTs, e inclui também mulheres fora do período reprodutivo (BASTOS, 2000).

\section{CONSIDERAÇÕES FINAIS}

Assim se configura o terreno em que se inscreve a AIDS, no qual se entrelaçam normas e interdições à sexualidade, características femininas e masculinas dessa sexualidade, relações de gênero e de poder, valorização da fidelidade, sentimentos como o amor e códigos morais. Neste cenário se dá o trabalho dos profissionais da saúde em geral e da Enfermagem em particular, cuja referência localiza-se na sexualidade heterossexual bem delimitada pela biologia e tratada dentro do modelo biomédico que tem como referência, no mais das vezes, o que é instituído como 'normal' para masculino e feminino. Este normal fixa homens e mulheres em pólos opostos, rotulando-os como vilão e 'vítima', o que tem custos para ambos e, em certa medida, influencia nossas abordagens de prevenção, de diagnóstico e de tratamento.

É urgente que abandonemos essa visão polarizada vilão-vítima. A compreensão das relações de gênero pode nos ajudar neste objetivo abrindo-nos a possibilidade de perceber que múltiplos fatores contribuem para que os casais percebam a AIDS como muito distante de suas vidas e, como conseqüência, não se percebam com necessidade de tomar medidas de auto-proteção. Dentre esses fatores é preciso considerar a construção sócio-cultural dos papéis masculino e feminino, as características da masculinidade e da feminilidade, o tratamento diferenciado dispensado ao exercício da sexualidade masculina e feminina, as características do poder existente em uma relação e a compreensão da AIDS associada a grupos/comportamentos de risco ainda fortemente presente. Isso traz dificuldades para as iniciativas de prevenção baseadas principalmente na noção de sexo mais seguro, o que implica também no uso do preservativo masculino o qual é muito mais controlado pelo homem do que pela mulher. Assim, a negociação do uso do preservativo (se houver) se dá "no contexto das já antigas desigualdades que estruturam as relações de poder e de gênero na sociedade brasileira" (REDE NACIONAL FEMINISTA apud PARKER e GALVÃO, 1996, p. 10).

Os métodos de prevenção existentes para prevenção da AIDS dependem da cooperação do parceiro (homem ou mulher): o preservativo masculino e a monoparceria sexual, o que nos remete às diferenças na socialização de homens e mulheres em todos os setores do viver e especialmente na sexualidade, comentadas anteriormente e às assimetrias de gênero existentes no casal, as quais dificultam o diálogo sobre o preservativo e a negociação do uso do mesmo. Visto como método contraceptivo, o preservativo masculino solicita a participação masculina na contracepção, tarefa geralmente assumida pelas mulheres com utilização de métodos contraceptivos integralmente controlados por elas e que excluem a participação masculina, dispensam o diálogo e lhes possibilitam maior liberdade sexual. Aliado a isso, 
a existência de preconceitos em torno do preservativo como, por exemplo, a idéia de que reduz o prazer sexual, torna mais difícil a negociação do seu uso.

A emergência da AIDS e sua expansão colocaram progressivamente em evidência as relações heterossexuais e o desconhecimento que as cerca. Nestas relações marcadas por gênero e poder, pontuadas por silêncios e pressuposições, a AIDS coloca em foco a necessidade de diálogo no casal, da compreensão do relacionamento sexual como um espaço de trocas entre o casal em que as assimetrias de gênero podem ser atenuadas, da percepção da gravidez como mais uma preocupação no relacionamento, da maior participação do homem na contracepção, dentre outras tantas.

Neste cenário, a expressão 'auto-proteção' largamente usada parece incompatível, pois evoca uma preocupação egoística consigo em detrimento do outro. Talvez pudéssemos falar em cuidado mútuo, o que não implicaria um cuidando do outro antes de cuidar de si, ou então cuidar de si antes de cuidar do outro, mas cuidar de si ao mesmo tempo em que se está atento ao cuidado do outro.

O relacionamento de casais heterossexuais está no centro do crescimento da epidemia de AIDS no mundo todo. A necessidade de compreender estas relações a partir da compreensão de homens e mulheres que as vivem nos possibilitará atuar em prevenção de uma maneira mais próxima do viver dos casais, diminuindo as possibilidades de termos nossa visão, nosso pensar e nosso fazer profissional obscurecido pela compreensão de homem, de mulher e de relacionamento normal que também temos, posto que circulamos pelas redes de poder e gênero que marcam a socialização de homens e mulheres em nossa sociedade.

A compreensão das questões de gênero que marcam estas relações pode abrir novas perspectivas para a atuação da enfermagem em educação em saúde, justamente por permitir a compreensão de que não é suficiente orientar o uso do preservativo ou a fidelidade, mas envolver-se em diálogo com homens e mulheres discutindo os diversos aspectos acima pontuados destas relações. Talvez desta forma demonstremos uma ação menos prescritiva e mais compreensiva que nos coloque mais próximos de homens e mulheres para conversar sobre questões íntimas de cada um (que não envolvem apenas suas práticas sexuais) tão importantes na prevenção das DST/AIDS.

ABSTRACT: That is a reflexion about the increase of HIV/aids epidemia between people of heterossexual orientation, especially ones involved in stable affectiv-sexual relationship, and about the interactions between gender and power relation to this increasing. From this point, we thing about the health education for prevention of DST/AIDS in everyday nursing practice, point out the need of adoption of a less prescretive and more understanding position to permit the dialog with men and women about many questions of their private life involved in the determnination of their vulnerability to DST/aids.

KEYWORDS: gender; power; couple relations; AIDS prevention.

\section{REFERÊNCIAS BIBLIOGRÁFICAS}

BASTOS, Francisco Inácio. A feminização da epidemia da aids no Brasil: determinantes estruturais e alternativas de enfrentamento. Rio de Janeiro: ABIA, 2000. Coleção ABIA-Saúde Sexual e Reprodutiva. V.3.

BARBOSA, Regina Maria. HIVIAIDS, transmissão heterossexual e métodos de prevenção controlados por mulheres. Rio de Janeiro: ABIA, 2000. Coleção ABIA - Saúde Sexual e Reprodutiva. V.2

CAMPOS, Regina Célia Pereira. AIDS: trajetórias afetivo-sexuais das mulheres. In: BRUSCHINI, Cristina; HOLLANDA, Heloísa Buarque de. Horizontes plurais: novos estudos de gênero no Brasil. São Paulo: FCC, 1998.

FOUCAULT, Michel. Microfísica do poder. Rio de Janeiro: Graal, 1995.

Vigiar e punir: nascimento da prisão. 24. ed. Petrópolis: Vozes, 2001.

GUIMARÃES, Carmem Dora. AIDS no feminino: porque a cada dia mais mulheres contraem aids no 
Brasil? Rio de Janeiro: Editora da UFRJ, 2001.

LOURO, Guacira Lopes. Gênero, sexualidade e educação. 2. ed. Petrópolis: Vozes, 1998.

PAIVA, Vera. Fazendo arte com a camisinha: sexualidades jovens em tempos de AIDS. São Paulo: Summus, 2000.

PARKER, Richard G.; GALVÃO, Jane. Introdução. In: PARKER, Richard G.; GALVão, Jane(org.). Quebrando o silêncio: mulheres e AIDS no Brasil. Rio de Janeiro: Relume-Dumará, 1996. p.7.
. Corpos, prazeres e paixões. Rio de Janeiro: Best Seller, 1991.

VILLELA, Wilza. Refletindo sobre a negociação sexual como estratégia de prevenção para a AIDS entre mulheres. In: PARKER, Richard G.; GALVÃO, Jane(org.). Quebrando o silêncio: mulheres e AIDS no Brasil. Rio de Janeiro: Relume-Dumará, 1996.
ENDEREÇO DAS AUTORAS Rua Liberal Bresolla, 30 Bairro Bela Vista Concórdia/SC 89.700-000

E-mail: val@uncnet.br 